\title{
Surgical treatment of Loeys-Dietz syndrome in a 3-year-old: case report and review of literature
}

\author{
Miao Tian ${ }^{1,2}$, Ming-Sing Si ${ }^{3}$, Yong Zhang', Yu Ding ${ }^{2}$, Jimei Chen ${ }^{2}$ \\ ${ }^{1}$ Department of Cardiac Surgery, Guangdong Provincial People's Hospital, School of Medicine, South China University of Technology, Guangzhou, \\ China; ${ }^{2}$ Department of Cardiac Surgery, Guangdong Provincial Cardiovascular Institute, Guangdong Provincial Key Laboratory of South China \\ Structural Heart Disease, Guangdong Provincial People's Hospital, Guangdong Academy of Medical Sciences, Guangzhou, China; ${ }^{3}$ Department of \\ Cardiac Surgery, Section of Pediatric Cardiovascular Surgery, University of Michigan, Ann Arbor, MI, USA \\ Correspondence to: Jimei Chen. Department of Cardiac Surgery, Guangdong Provincial Cardiovascular Institute, Guangdong Provincial Key \\ Laboratory of South China Structural Heart Disease, Guangdong Provincial People's Hospital, Guangdong Academy of Medical Sciences, \\ Guangzhou, China. Email: jimei@hotmail.com.
}

\begin{abstract}
Aortic complications of Loeys-Dietz syndrome (LDS) rarely present in children. Here we describe a case of LDS type 2 in a 3 -year-old child with severe aortic root dilation and severe aortic regurgitation. A Bentall procedure combined with a Cabrol-type coronary modification was used to treat this child. In order to minimize the need for reintervention as the child grows. We chose a composite valve-graft by a St Jude Regent 21\# mechanical valve seated within a $24 \mathrm{~mm}$ Gore-Tex graft to finish the Bentall procedure. Echocardiographic studies demonstrated good valve and ventricular function at 1-year follow-up. This child is one of the youngest LDS patients to receive a Bentall procedure and the way using a composite valve-graft to finish the operation can provide a reference for the surgical strategies of such patients in the future. Children with LDS and severe aortic annulus dilatation combined with severe aortic valve regurgitation require early surgical intervention, and implantation of a mechanical valved-conduit can be utilized successfully. Life-long follow-up of the valvedconduit and arterial vessels of these patients is necessary. The experience gained from this case contributes to the management of the rare LDS patient who presents at an early age with aortic root and valve pathology. Close monitoring and early intervention are important.
\end{abstract}

Keywords: Loeys-Dietz syndrome (LDS); surgery; autosomal dominant inheritance; gene mutation; case report

Submitted May 25, 2020. Accepted for publication Sep 04, 2020.

doi: $10.21037 / \mathrm{tp}-20-146$

View this article at: http://dx.doi.org/10.21037/tp-20-146

\section{Introduction}

Loeys-Dietz syndrome (LDS) is an autosomal dominant disorder of the connective tissue that was described in 2005 (1). Patients with mutations in the TGFBR1, TGFBR2, TGFB2, $T G F B 3$, and $S M A D 3$ genes were noted to present with phenotypical features of LDS. LDS affects tissues and organs throughout the body, especially the great arteries. Rapidly progressive aortic aneurysmal disease is a distinct feature of LDS and thus mandates close monitoring of these patients. Early prophylactic surgery is crucial to avoid catastrophic aortic complications and achieve a good longterm prognosis (2). Here we present a case of a young child with LDS who was implanted a composite valve-graft by a St Jude Regent 21 \# mechanical valve seated within a $24 \mathrm{~mm}$ Gore-Tex graft to finish the Bentall procedure and achieved a favourable post-operative follow-up outcome, describe the presenting signs and symptoms, and discuss the clinical management. We present the following case in accordance with the CARE reporting checklist (3) (available at http:// dx.doi.org/10.21037/tp-20-146).

\section{Case presentation}

Written informed consent was obtained from the patient's parents. All procedures performed in studies involving 
Table 1 Transthoracic echocardiogram (TTE) results of the aortic annulus, aortic sinus, sinotubular junction and ascending aorta at different age

\begin{tabular}{|c|c|c|c|c|c|c|}
\hline & $\begin{array}{l}\text { Aortic annulus } \\
\qquad(\mathrm{mm})\end{array}$ & $\begin{array}{l}\text { Aortic Sinus } \\
\qquad(\mathrm{mm})\end{array}$ & $\begin{array}{l}\text { Sinotubular junction } \\
\qquad(\mathrm{mm})\end{array}$ & $\begin{array}{l}\text { Ascending aorta } \\
(\mathrm{mm})\end{array}$ & $\begin{array}{l}\text { Aortic valve } \\
\text { regurgitation }\left(\mathrm{cm}^{2}\right)\end{array}$ & LVEF (\%) \\
\hline 22 months & 23 & 29 & 17.6 & 13.9 & 4.3 & 77 \\
\hline 24 months & 22 & 29 & - & 16 & 5.6 & 80 \\
\hline 30 months & 21.6 & 29.4 & - & 18.2 & 4.3 & 64 \\
\hline
\end{tabular}
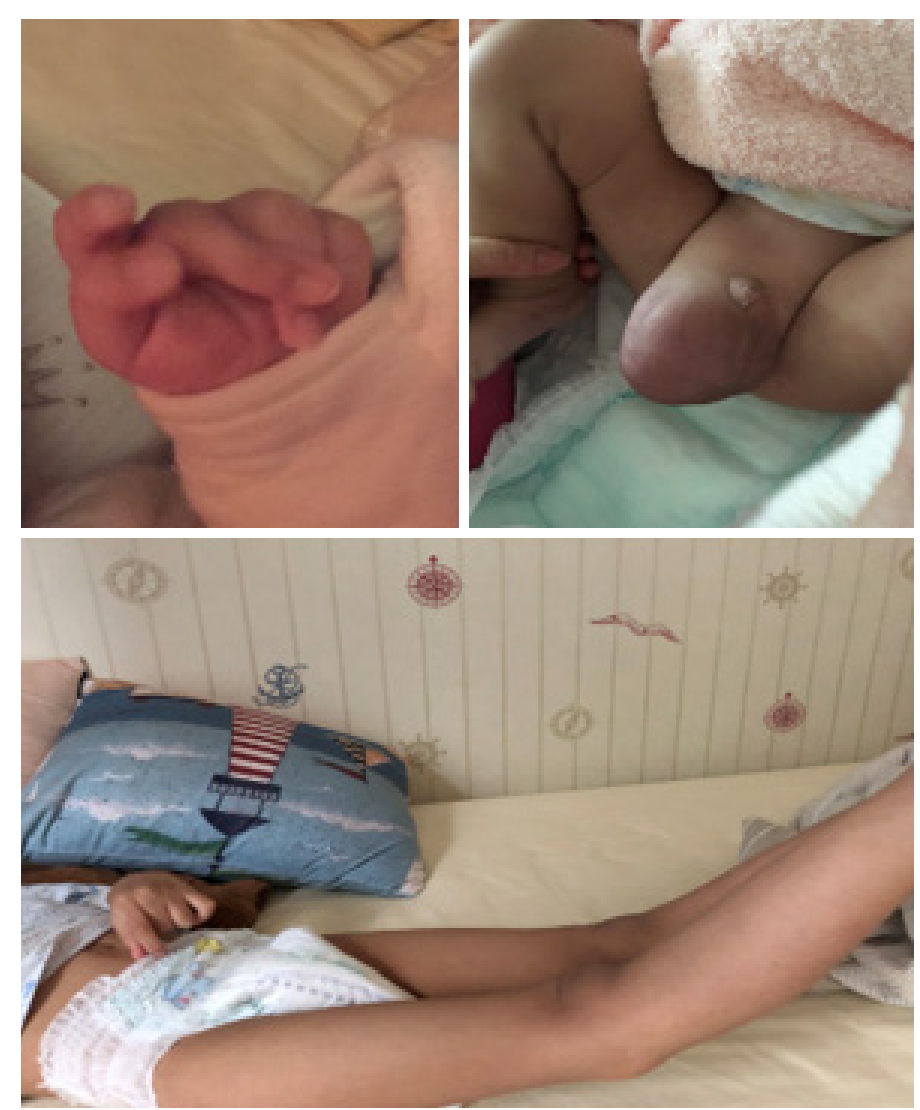

Figure 1 Pediatric LDS patient with middle finger spasm bilaterally, inguinal hernia, and hyperextension of the knees. LDS, loeys-Dietz syndrome.

human participants were in accordance with the ethical standards of the Guangdong Provincial People's Hospital ethical review committee and with the Helsinki Declaration (as revised in 2013). Written informed consent was obtained from the patient's parents for publication of this Case report and any accompanying images. A three-and-half yearold-boy with a history of LDS was referred for surgical intervention after a transthoracic echocardiogram (TTE) demonstrated a dilated aortic annulus (diameter: $23 \mathrm{~mm}$, $\mathrm{z}$ score 11.59) and ascending aorta (diameter:18.6 mm, z score 3.99) as well as severe regurgitation and left ventricle dilation and decreasing systolic function (Table 1). Notably, on physical examination, he was noted to have middle finger spasm bilaterally, inguinal hernia, and hyperextensibility of the knees (Figure 1). At 7 months of age, an echocardiogram demonstrated left ventricular enlargement, a patent 
Table 2 Gene sequencing indicated a heterozygous missense mutation of the TGFBR2 gene: 1634G-->T, leading to an amino acid change of C545F

\begin{tabular}{|c|c|c|c|c|c|c|c|c|c|c|c|}
\hline Gene & $\begin{array}{c}\text { Chromosome } \\
\text { location }\end{array}$ & $\begin{array}{c}\text { Transcript } \\
\text { number }\end{array}$ & Exon & $\begin{array}{l}\text { Nucleotide } \\
\text { change }\end{array}$ & $\begin{array}{l}\text { Amino acid } \\
\text { change }\end{array}$ & $\begin{array}{l}\text { Homozygous/ } \\
\text { heterozygous }\end{array}$ & $\begin{array}{l}\text { Normal } \\
\text { frequency }\end{array}$ & $\begin{array}{l}\text { Pathogenicity } \\
\text { analysis }\end{array}$ & $\begin{array}{c}\text { Genetic } \\
\text { way }\end{array}$ & $\begin{array}{l}\text { Disease/ } \\
\text { phenotype }\end{array}$ & $\begin{array}{l}\text { Sources of } \\
\text { variation }\end{array}$ \\
\hline TGFBR2 & Chr3-30732946 & $\begin{array}{c}\text { NM_00 } \\
1024847\end{array}$ & Exon8 & c. $1634 \mathrm{G}>\mathrm{T}$ & p.C545F & het & - & $\begin{array}{l}\text { Likely_ } \\
\text { pathogenic }\end{array}$ & $A D$ & LDS (type 2) & $\begin{array}{c}\text { Spontaneous } \\
\text { mutation }\end{array}$ \\
\hline
\end{tabular}

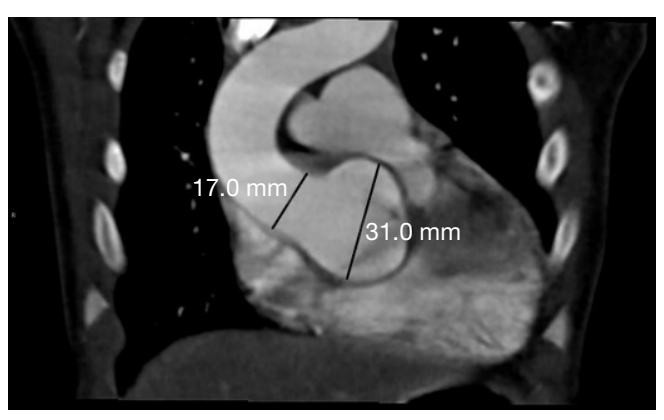

Figure 2 CT scan at 2 years of age demonstrated a dilated aortic annulus and ascending aorta.

foramen ovale, aortic sinus dilatation (diameter: $24 \mathrm{~mm}$ ), ascending aortic dilation (diameter: $14 \mathrm{~mm}$ ), and moderate regurgitation of aortic valve (regurgitation area: $1.5 \mathrm{~cm}^{2}$ ). Based on these echocardiogram findings, gene sequencing was performed at that time and revealed a heterozygous missense mutation of the TGFBR2 gene: $1634 \mathrm{G}-->\mathrm{T}$, leading to an amino acid change of C545F (Table 2). Parental gene sequencing did not reveal any abnormalities. Given the physical signs, echocardiogram findings, and genomic studies, a diagnosis of LDS type 2 (OMIM: 610168) was made.

The child's aortic regurgitation was monitored closely, and serial TTE over the first three years of life demonstrated progressive dilation of the aortic annulus, aortic sinus, sinotubular junction, and ascending aorta (Table 1). Further, aortic regurgitation progressively worsened (Table 1). A CT of the head and neck demonstrated an enlarged skull and no obvious dilation or deformity of the head and neck blood vessels. A CT at 2 years of age demonstrated a dilated aortic annulus and ascending aorta (Figure 2).

Because of the severe aortic valve regurgitation resulting in rapid and progressive left ventricle dilation, the patient underwent a Bentall procedure at 3 years and 3 months of age. His extremely dilated aortic annulus was felt to be a contraindication to a valve sparing aortic root replacement procedure. After coronary buttons were harvested and diseased sinus tissue resected (Figure $3 A, B, C$ ), a composite valve-graft by a St Jude
Regent 21\# mechanical valve seated within a $24 \mathrm{~mm}$ Gore-Tex graft was implanted (Figure 3D,E,F). Given the distance between the coronary buttons and the aortic graft, Cabrol extension of the coronary arteries was performed (Figure 3G,H,I). Postoperative transesophageal and transthoracic echocardiography demonstrated good aortic valve function with no perivalvular regurgitation and laminar coronary flow. The cardiopulmonary bypass time was $193 \mathrm{~min}$ and the aortic cross clamp time was $121 \mathrm{~min}$. Pathological examination revealed that the aortic valve had undergone degeneration with interstitial fibrous hyperplasia, focal collagenization, myxoid degeneration and focal calcification (Figure 4A). Furthermore, the resected aneurysmal aorta revealed a thin wall with inflammatory infiltrate (Figure 4B). The patient had an uneventful postoperative recovery and was discharged on postoperative day 12 with losartan and warfarin. The timeline of this case was shown in Figure 5.

At 3 months follow-up, TTE demonstrated normal left ventricle function, a functioning prosthetic aortic valve and mild tricuspid regurgitation. The proximal part of the ascending aorta diameter was $21.2 \mathrm{~mm}$ and a mild gradient was measured in the proximal aortic arch (Vmax $1.6 \mathrm{~m} / \mathrm{s}$ ). At 1-year post repair, the patient continued to do well with improved tricuspid regurgitation, stable aortic dimensions, a functioning prosthetic aortic valve and normal left ventricle function.

\section{Discussion}

LDS was originally described in 16 individuals from ten families (4). Patients with LDS exhibit a variety of features, mainly involving the cardiovascular, musculoskeletal and central nervous systems (5). TGFBR1 and TGFBR2 mutations were initially shown to cause LDS, with subsequent pathogenic mutations identified in $S M A D 3$, TGFB2, and TGFB3. Pathogenic mutations in all of these genes, which encode mediators of the TGF signaling pathway, result in loss of function of the protein product (6), causing elastin disarray, loss of elastic fiber architecture and increased collagen expression in the aortic media of 

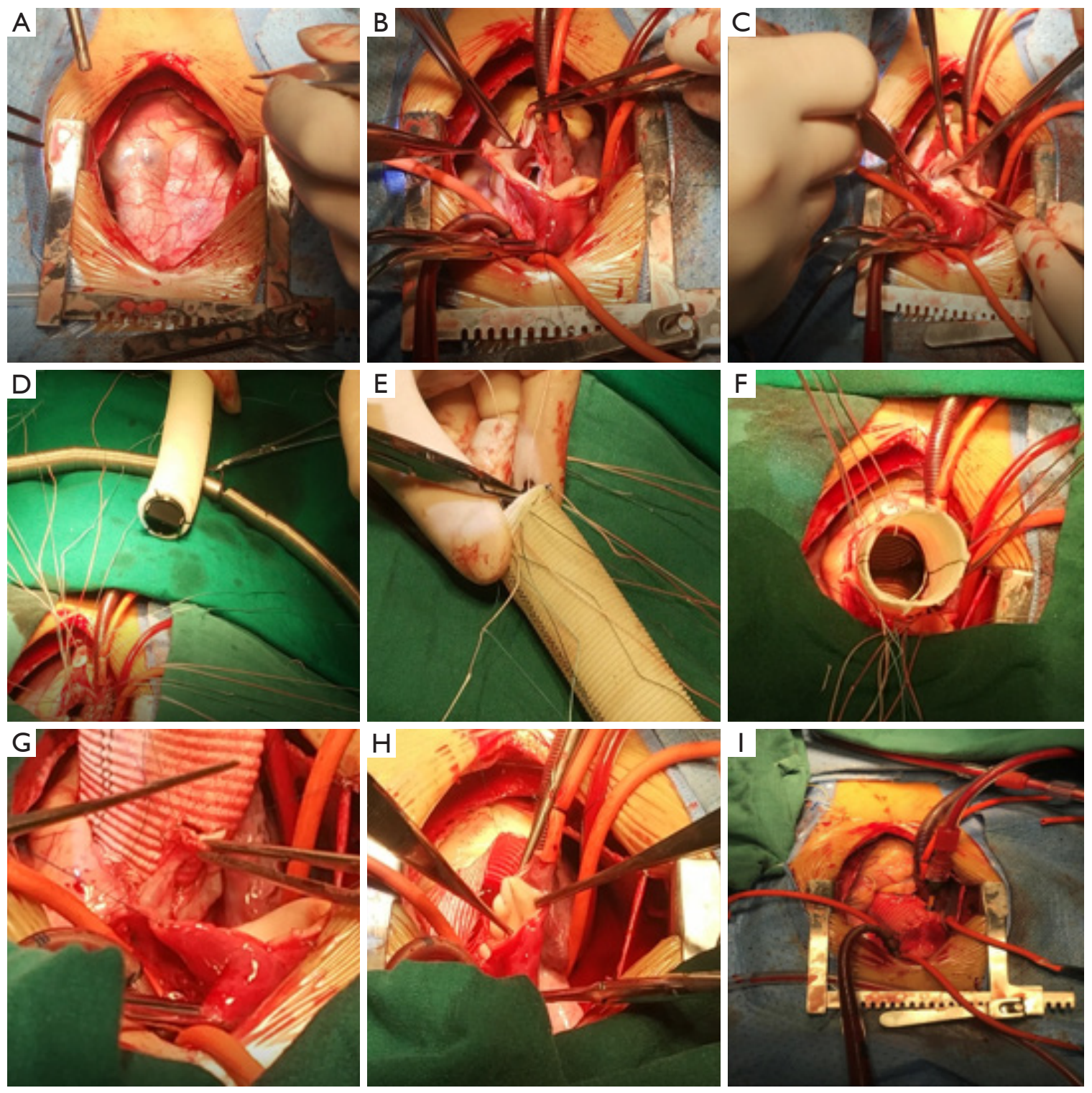

Figure 3 Bentall procedure performed with a composite valve-graft comprised of a St Jude Regent 21 \# mechanical valve within a 24 mm Gore-Tex graft. (A) A dilated aortic annulus (diameter: $30 \mathrm{~mm}$ ) and ascending aorta. (B) The aortic valve and aneurysmal aorta were excised. (C) Harvesting of coronary buttons. (D,E,F) A composite valve-graft was created with a St Jude Regent $21 \#$ mechanical valve in a 24 mm Gore-Tex graft was implanted. (G) Cabrol extension of the coronary arteries was performed. (H and I) The Gore-Tex graft was anastomosed to the ascending aorta.

patients. The aortic wall is characterized by medial diffuse degeneration and elastin fragmentation (7). Because of these structural changes, the vascular media weakens and makes the aorta prone to aneurysmal dilation and dissection $(4,5,8)$.

Half of LDS patients with severe craniofacial features are at particularly high risk, known to have aneurysm rupture at an early age and at smaller dimensions than those with other aneurysm syndromes $(1,4)$. It has been reported that patients with LDS undergo cardiovascular operations earlier (mean age, 16.9 years) and die earlier (mean age, 22.6 years) but have a lower intraoperative mortality rate (9). The reported median age at first dissection for patients with LDS is 26.7 years (10) and the mean age of death was 26 years and the median survival was 37 years. The leading 

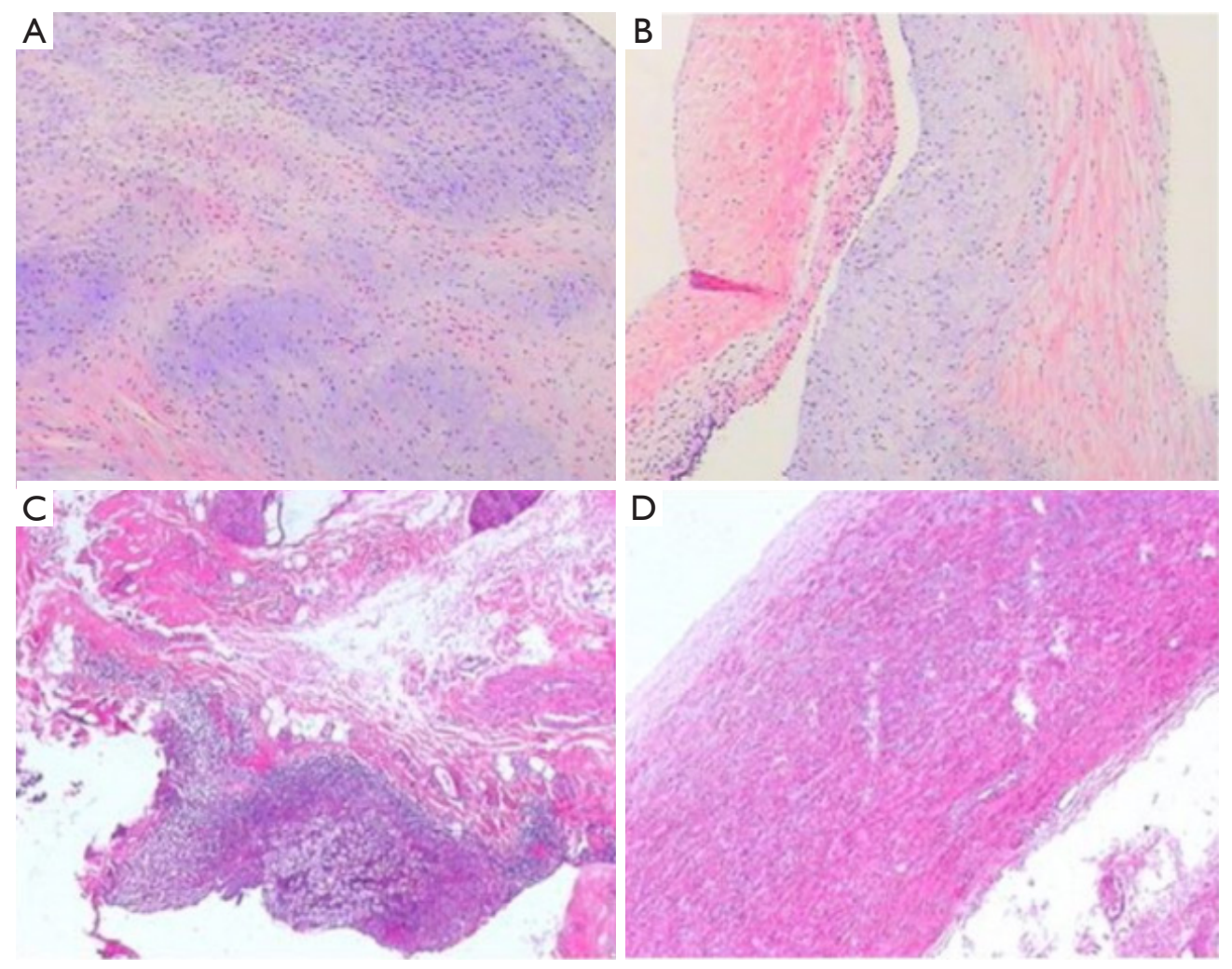

Figure 4 Pathological examination of the aortic valve. (A,B) Degenerative changes with interstitial fibrous hyperplasia, focal collagenization, myxoid degeneration and focal calcification (magnification 40x). (C,D) Inflammatory infiltrate was also present in the resected aneurysmal aorta (magnification 40x).

cause of death for LSD was dissection of the thoracic aorta (67\%), abdominal aorta (22\%), and the cerebral vasculature (7\%) (4). The vascular phenotype of LDS, characterized by aneurysmal changes and tortuosity of the arteries, is not limited to the aortic root, and lifelong serial imaging of the entire arterial tree, both systemic and pulmonary, is mandatory (11).

The decision to undergo aortic surgery is typically based on the absolute dimension of the aorta, rate of progression, aortic valve function, severity of noncardiac features, family history, and information about genotype $(4,12)$. A clinical study including 53 LDS patients, 33 of whom underwent aortic surgery noted that close monitoring and early prophylactic interventions were the key to avoid aortic catastrophe and to achieve a good long-term prognosis (2).

This child is one of the youngest LDS patients to receive a Bentall procedure. Progressive aortic dilation and severe aortic valve insufficiency mandated early intervention. Fortunately for this patient, we were able to implant an adult-sized valved conduit. However, the consequence of this operation is that this child will need life-long anticoagulation.

Early genetic testing is warranted if the physical examination and history are suggestive of LDS. Further, genetic testing will permit the differentiation of these patients from those with Marfan syndrome. Close follow up is required for children with LDS, provided there is no life-threatening dissection or aneurysm in the aorta and the function of the aortic valve is not significantly impaired.

Children with LDS and aortic dilatation and aortic valve regurgitation should be closely followed. Treatment with a Bentall procedure or valve sparing root replacement are required and adult-sized grafts and valves will minimize the need for reintervention as the child grows. Continued lifelong follow-up in these patients is needed to monitor the rest of the arterial tree, which is susceptible to aneurysmal dilation and complications and may require prophylactic intervention. 


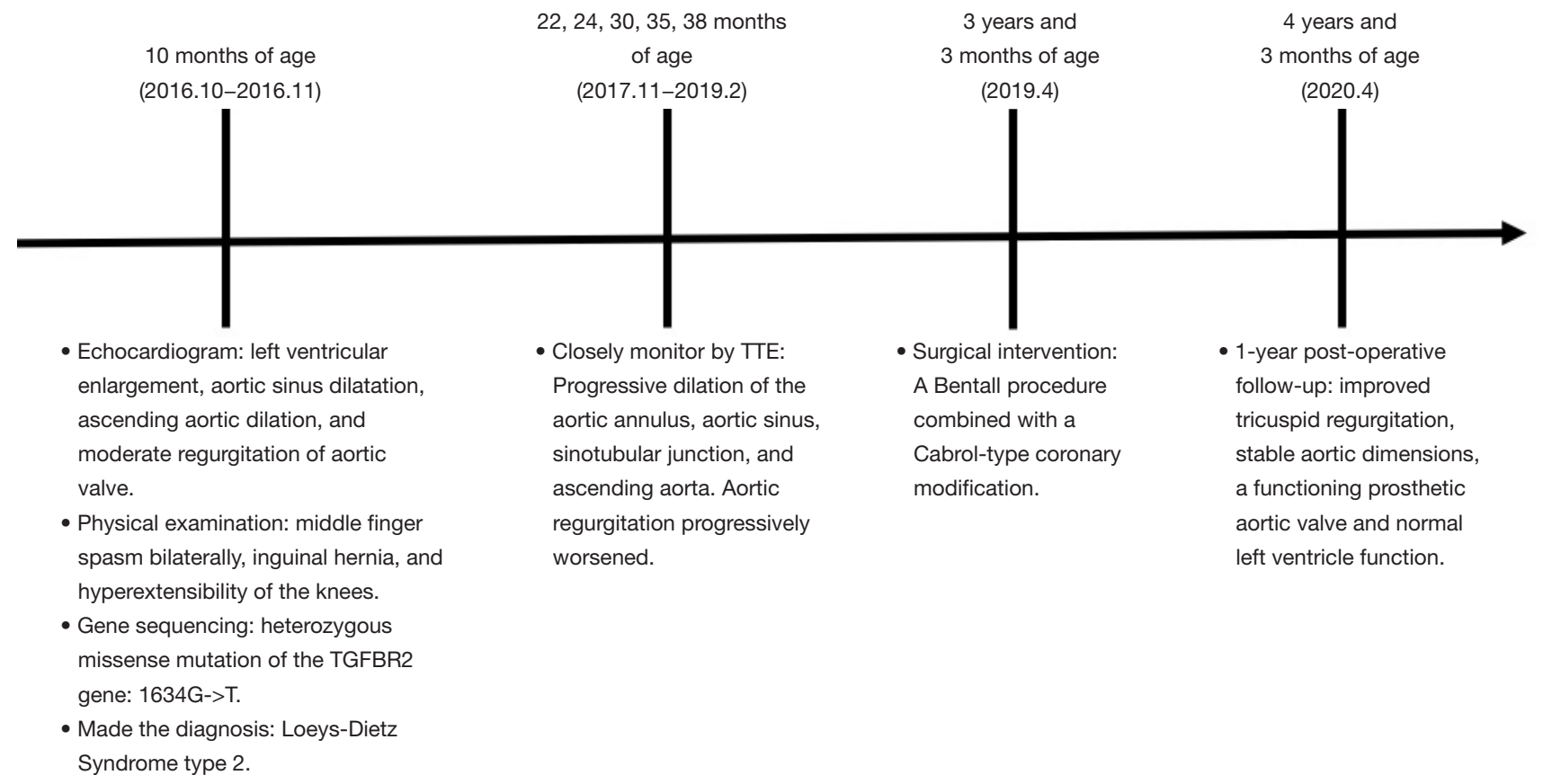

Figure 5 The timeline of this case.

The limitation of this study is that this patient should need life-long anticoagulation and we can't predict whether and when other arteries need intervention. We need the long-term follow-up consequence to evaluate our surgical strategies.

\section{Acknowledgments}

Funding: This work was supported by the National Key R\&D Program of China (2018YFC1002600) and the Science and Technology Planning Project of Guangdong Province, China (2017A070701013, 2017B090904034, 2017B030314109, 2019B020230003) and the Guangdong peak project (DFJH201802)

\section{Footnote}

Reporting Checklist: The authors have completed the CARE reporting checklist. Available at http://dx.doi.org/10.21037/ tp-20-146

Conflicts of Interest: All authors have completed the ICMJE uniform disclosure form (available at http://dx.doi. org/10.21037/tp-20-146). MSS serves as an unpaid Deputy Editors-in-Chief of Translational Pediatrics from Dec 2018 to Nov 2020. The other authors have no conflicts of interest to declare.
Ethical Statement: The authors are accountable for all aspects of the work in ensuring that questions related to the accuracy or integrity of any part of the work are appropriately investigated and resolved. All procedures performed in studies involving human participants were in accordance with the ethical standards of the Guangdong Provincial People's Hospital ethical review committee and with the Helsinki Declaration (as revised in 2013). Written informed consent was obtained from the patient's parents for publication of this Case report and any accompanying images.

Open Access Statement: This is an Open Access article distributed in accordance with the Creative Commons Attribution-NonCommercial-NoDerivs 4.0 International License (CC BY-NC-ND 4.0), which permits the noncommercial replication and distribution of the article with the strict proviso that no changes or edits are made and the original work is properly cited (including links to both the formal publication through the relevant DOI and the license). See: https://creativecommons.org/licenses/by-nc-nd/4.0/.

\section{References}

1. Loeys BL, Chen J, Neptune ER, et al. A syndrome of altered cardiovascular, craniofacial, neurocognitive and 
skeletal development caused by mutations in TGFBR1 or TGFBR2. Nat Genet 2005;37:275-81.

2. Aftab M, Cikach FS, Zhu Y, et al. Loeys-Dietz syndrome: Intermediate-term outcomes of medically and surgically managed patients. J Thorac Cardiovasc Surg 2019; 157:439-50.e5.

3. Riley DS, Barber MS, Kienle GS, et al. CARE guidelines for case reports: explanation and elaboration document. J Clin Epidemiol 2017;89:218-35.

4. Loeys BL, Schwarze U, Holm T, et al. Aneurysm syndromes caused by mutations in the TGF-beta receptor. N Engl J Med 2006;355:788-98.

5. Choo JT, Tan TH, Lai AH, et al. Loeys-Dietz syndrome: a Marfan-like syndrome associated with aggressive vasculopathy. Singapore Med J 2009;50:e353-7.

6. Zimmermann MT, Urrutia RA, Blackburn PR, et al. Novel Pathogenic Variant in TGFBR2 Confirmed by Molecular Modeling Is a Rare Cause of Loeys-Dietz Syndrome. Case Rep Genet 2017;2017:7263780.

Cite this article as: Tian M, Si MS, Zhang Y, Ding Y, Chen J. Surgical treatment of Loeys-Dietz syndrome in a 3-year-old: case report and review of literature. Transl Pediatr 2020;9(5):695-701. doi: 10.21037/tp-20-146
7. Iba Y, Minatoya K, Matsuda H, et al. Surgical experience with aggressive aortic pathologic process in Loeys-Dietz syndrome. Ann Thorac Surg 2012;94:1413-7.

8. Sim HT, Seo DJ, Yu JJ, et al. Valve Sparing Aortic Root Replacement in Children with Loeys-Dietz Syndrome. Korean J Thorac Cardiovasc Surg 2015;48:272-6.

9. Nakajima T, Tachibana K, Miyaki Y, et al. Acute dilatation of the ascending aorta and aortic valve regurgitation in LoeysDietz syndrome. Ann Thorac Surg 2014;97:2188-90.

10. Inoue $\mathrm{Y}$, Minatoya $\mathrm{K}$, Oda T, et al. Total Aortic Replacement for a 9-Year-Old Boy With Loeys-Dietz Syndrome. Ann Thorac Surg 2016;101:1185-8.

11. Rizzo S, Stellin G, Milanesi O, et al. Aortic and Pulmonary Root Aneurysms in a Child With Loeys-Dietz Syndrome. Ann Thorac Surg 2016;101:1193-5.

12. Arslan-Kirchner M, Epplen JT, Faivre L, et al. Clinical utility gene card for: Loeys-Dietz syndrome (TGFBR1/2) and related phenotypes. Eur J Hum Genet 2011;19. doi:10.1038/ejhg.2011.68. 